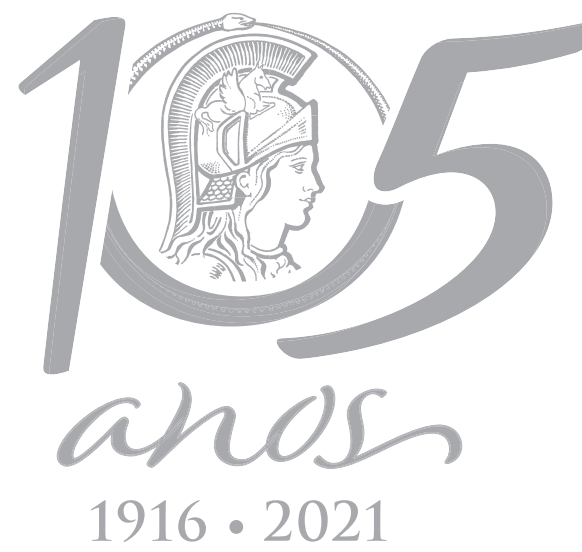

\title{
ECOSYSTEMS
}

\section{Drivers of nest survival in the Tawny-bellied Seedeater Sporophila hypoxantha (Aves: Thraupidae): time-specific factors are more related to success than ecological variables}

\author{
ISMAEL FRANZ \& CARLA S. FONTANA
}

\begin{abstract}
Tawny-bellied Seedeater (Sporophila hypoxantha) is an endangered (in Brazil) grassland dependent species, whose breeding success remains poorly known hampering conservation measures on its breeding grounds. Here we analyze the nest survival of the species in relation to temporal and environmental variables over three breeding seasons in hilly dry grasslands in southern Brazil. The apparent nest success was $40 \%$, and MARK survival $20 \%$. Predation was the main cause of failure, affecting $55 \%$ of the unsuccessful nests, followed by desertion, infestation by Philornis fly larvae, cattle trampling and burning. The productivity was 1.77 young per pair. Best models include time-specific factors (nest age and time of breeding season), reflected by a gradual reduction in nest survival over the nesting cycle, accompanied by an increase in temperature, subcutaneous larvae infestation, and predation. Nest site characteristics did not influence nest survival. Predation is more prevalent in the nestling rearing period than during incubation. This tendency may be caused by an increase in the activity in the nests, as is predicted by the Skutch hypothesis. The conclusion that time-specific factors influence nest survival more than ecological variables is important to plan on seasonally dependent conservation and management measures.
\end{abstract}

Key words: breeding, nesting, predation, productivity, reproductive success.

\section{INTRODUCTION}

Nest predation is the most important single factor reducing nest success (Ricklefs 1969, Willis 1974, Roper 1992) and therefore may often be an important driver of life history evolution (Martin 2004). The higher rate of predation shown by Neotropical birds in relation to patterns in the northern hemisphere has been debated (Ricklefs 1969, Oniki 1979, Skutch 1985, Martin 1995). The simple differences in clutch size, a widely discussed and tested attribute among North and South American birds, have been well-known since the study by Moreau (1944), although variations between latitudes are in need of a major revision (Martin et al. 2000a).
Nest survival varies spatially and temporally due to differences in climate, predator community and human disturbance (Skutch 1985). Timespecific factors, such as nest age or time of breeding season may be related to variation in the nest predation risk for many species (Grant et al. 2005). An increase in predation during the nestling phase (the age-specific effect) may be due to increased activity at the nest as a consequence of feeding nestlings (the Skutch hypothesis, Skutch 1949). The selection pressure exerted by predation would force pairs to visit the nest less often and would thus restrict the potential clutch size (Martin 2011). Lack (1947) proposed an alternative to Skutch, stating that 
the latitudinal difference in clutch size would actually be related to food availability and the ability of the parents to obtain it. Longer day length would allow individuals to find more food each day and, therefore, feed more nestlings. Testing Skutch's predictions, Roper \& Goldstein (1997) demonstrated that the activity at a nest does not increases its chance of predation, which elucidates the need to rethink the role of predation in the evolution of tropical and temperate life histories. Indirect factors such as habitat features (i.e. whether or not variation in the nest height from the ground and support plant species favor nest concealment) influence the probability of predation and, therefore, reproductive success (Slagsvold 1982, Martin \& Roper 1988).

While $80 \%$ of all passerines occur in tropical latitudes, the disproportional majority of studies that serve as a theoretical base for the understanding of behavioral ecology in birds have been conducted with north-temperate zone species (Stutchbury and Morton 2008). These authors estimate the proportion of northtemperate vs. tropical bird studies to be >100:1. Martin (1996) called the state of knowledge about the life history traits of tropical/southern hemisphere birds as "extremely poor." The majority of comparisons are drawn between the northern hemisphere and the tropics, and subtropical regions (south-temperate) are even more poorly studied. In addition, grassland areas are weakly represented in comparative analyses (Robinson et al. 2010). Although some studies have provided estimates of breeding success for Sporophila seedeaters, typical representatives of open habitats in southern South America (Silva 1999), just Repenning \& Fontana (2016) inquired into the factors that are related to nest survival using modeling (on that case, for the Tropeiro Seedeater S. beltoni).
Here we estimate the nest survival of Tawnybellied Seedeaters Sporophila hypoxantha (Aves, Thraupidae) in Brazilian subtropical grasslands and compare time-specific factors, i.e. nest age and time of the breeding season, and ecological variables (e.g. nesting traits and concealment assessments) that apparently influence nest survival. For this, we employed models that include combinations of temporal, spatial and ecological factors.

\section{MATERIALS AND METHODS}

\section{Study site and species}

The study was conducted in the Campos de Cima da Serra region (Brazilian Subtropical Highland Grasslands, sensu Iganci et al. 2011), in dry grasslands that occur along the LavaTudo river, in the municipalities of São Joaquim and Lages (considered two subareas in the analyses), southeastern Santa Catarina State, southern Brazil (central point: $28^{\circ} 18^{\prime} \mathrm{S}, 50$ 으 17' W). The altitude varies from 800 to $1,000 \mathrm{~m}$ a.s.l. among field sites and the vegetation is rich in Asteraceae shrubs, grasses such as Sorghastrum, Andropogon, Paspalum and Setaria spp. and the thorny "eryngo" Eryngium horridum (Apiaceae). See a detailed description of the study site in Franz \& Fontana (2013).

Average monthly temperature is $13.3^{\circ} \mathrm{C}$ (coldest region in Brazil) and cumulative year rainfall is $1,609 \mathrm{~mm}$ with no remarkable seasonality. Climatic data used in our analysis were obtained from the meteorological station of the National Institute of Meteorology (INMET), located in São Joaquim, around $33 \mathrm{Km}$ from the study area.

In southern Brazil, the breeding season of the Tawny-bellied Seedeater lasts about 100 days, from the first week of November until the end of February (Franz \& Fontana 2013). Females arrive a few days after the males, 
which arrive in the study area the first week of November and quickly establish territories. The nest is constructed slightly above the ground $(\sim 40 \mathrm{~cm})$ and is camouflaged by shrubs such as Symphyopappus, Vernonanthura, Baccharis and Stevia spp. The clutch size is two but may be three in some cases, and incubation lasts for 12 days. Nestlings are fed by the pair (the males feed nestlings once they are older) and fledge the nest after 9-10 days (Franz \& Fontana 2013), which is similar to the timing in resident populations in Argentina (Di Giacomo 2005, Facchinetti et al. 2008). This grasslanddependent species is considered as endangered in Brazil (Vulnerable; ICMBio 2018).

\section{Field procedures}

During three breeding seasons (2007-2010), we conducted intensive nest-searching from the first week of November until March, in which we observed the behavior of females in territories defended by males (Martin \& Geupel 1993). Each nest was marked with small biodegradable colored tape 5-10 $\mathrm{m}$ from the nest and a point location with GPS. In order to verify the content and determine the activity status of nests, we visited each nest every 2-6 days until it became inactive (success or predated/deserted) and eggs or nestlings were quantified. We considered incubation the period between the laying of the first egg and the hatching of the first chick (Facchinetti et al. 2008, Franz \& Fontana 2013) and nestling period from the hatching of the first egg until the first nestling fledged the nest. The nests and contents were not manipulated except for a few nestlings that were banded after reaching seven days in age. For nests found during incubation, we estimated age by counting backwards from the hatching date. In nests found during the nestling period, nestlings were aged directly by morphology. We considered a nest successful if at least one nestling fledged. When a nest was found empty before the expected fledging date or with modified content, we classified it as unsuccessful. Predated nests were those in which eggs or nestlings disappeared before reaching the completion date for each phase of development, when a predation event was documented or when the nest was found deformed. Abandoned nests were those in which incubation exceeded the expected limit for egg hatching or were no longer visited by the female during construction.

The nest site characteristics that were evaluated and measured included support plant species, support plant height, support plant cover area (greater diameter $x$ lesser diameter in a vertical projection), nest height (from the border of the nest to the ground; these last three with a ruler) and an estimate of nest concealment (percentage of nest cover from breast height of the same observer, with 0 = completely uncovered and 100\% = completely covered by plants). Whenever possible in nests with young, we verified the occurrence of subcutaneous parasites (larvae of the dipteran Philornis seguyi) by quickly observing the nestlings and once a nest was inactive, searching for pupae in the nest walls.

\section{Data analysis}

We employed logistic regression models to evaluate the effect of the measured variables on daily nest survival rates. For this, we used the nest survival model available on the program MARK (White \& Burnham 1999). Initially, we continuously numbered each day of the reproductive period from day 1 on, which corresponds with the day in which the first nest was found with an egg during the three breeding seasons together. From the general sample of 69 nests encountered, we selected 47 nests in which we could reliably evaluate the information required for the method indicated 
by Dinsmore et al. (2002) that (1) the nests be correctly aged when found, (2) the nest fates be determined with confidence, (3) inspections did not influence survival, (4) the nest fates are independent and (5) there is homogeneity in the daily nest survival rates.

We divided the analysis into two sets of candidate models and each one of the covariates or sets was utilized to represent a priori hypothesis and predictions. In addition to the model that assumes a constant survival (null hypothesis model), the first set included a linear time trend model and a quadratic model (polynomial model that includes both a linear and squared value). We hypothesized that the DSR may vary temporally and if so, the time trend models should be favored. Survival may vary linearly, decreasing over the reproductive period in function of a tendency for there to be greater success in early breeders (Ainley \& Schlatter 1972), or curvilinearly (quadratic model), in which it may present a better pattern for the intermediate phase of the nesting season. The second set of models includes the covariates in "all combinations" (sensu Doherty et al. 2012) and is the set that formed the basis for choosing the models that best fit the data. Five nest-site variables were included as covariates (previously described in field procedures), which is nest height (no. of parameters $[K]=1$ ), plant height $(K=1)$, plant species $(K=2)$, plant cover $(K=1)$ and nest concealment $(K=1)$. We tested whether nest height or support plant or plant cover influenced nesting success. One spatial variable (in which of two study sites the nest was found, $K=1$ ) may reveal a preference for a specific area on a greater scale. The covariate year represents each of three reproductive seasons $(K=2)$ and the search for variations in DSR during each season. The covariate nest age (ageday1 sensu Rotella 2011), which represents the day of the first egg for each nest in relation to day 1 of the reproductive period $(K=1)$.

We compared the values of the candidate models to the constant/null model. To run the null model, we utilized the sin link function, and for those that included the covariates, the logit link function (Dinsmore et al. 2002). Once the competing models were constructed, the support was evaluated among the set of candidate models by means of Akaike's Information Criterion, adjusted for small sample sizes (AIC; Burnham \& Anderson 2002). According to these authors, only models with $\Delta \mathrm{AIC}_{\mathrm{c}} \leq 2$ show substantial support. We tabulated all of the models that were best supported than the null model of each set of competing models and excluded the rest. We utilized the Delta method (Seber 1982) on the 'emdbook' package (Bolker 2011) of the software $R$ version 2.14.0 ( $R$ Development Core Team 2011) to calculate and plot the product and variance from the $\beta$ values of the best model adopted. We did not perform the goodness of fit because there is no reliable GOF test for MARK users on nest survival; moreover, the saturated model fit the data well in these cases (Rotella 2011).

We calculated productivity per pair based on the number of fledglings produced in relation to the number of successful nests (Beier et al. 2017), which is the same of "productivity per nest" or "annual production of fledglings per female" in this species because pairs with successful nests never re-nested in the area (Franz \& Fontana 2013). We also calculated hatching rate, which is the number of eggs that hatch in relation to the number of eggs observed. In this way, we determined the frequency of occurrence of brood reduction (partial nest losses) during each phase of the nesting cycle.

To determine the correlations among the measured variables, we ran non-parametric tests for independent samples in the software 
BioEstat 5.0 (Ayres et al. 2007). We presented values as means \pm SD.

\section{RESULTS}

Of the 55 nests in which the final status was known (seven in 2007/2008, 26 in 2008/2009 and 22 in 2009/2010), 22 (40\%) were successful, with $57 \%, 35 \%$ and $41 \%$ during the seasons $2007 / 2008$, $2008 / 2009$ and 2009/2010, respectively. Of these 22 successful nests, 39 young fledged, which represents an average productivity of $1.77 \pm 0.52$ young per pair per reproductive season (this species is mainly one-brooded) in successful nests. Six pairs fledged one, 15 fledged two and one fledged three young. During the incubation period, partial nest loss occurred in five nests due to predation (one egg predated in clutches of two eggs [ $n=4]$, and two eggs predated in clutches of three eggs $[n=1])$. Of the 60 eggs studied during incubation, eight did not hatch, resulting in a hatch rate of $86 \%$ (or $14 \%$ of the eggs failed to hatch). During the nestling phase, partial losses occurred in six nests (18\%), always with the loss of one nestling.

The daily survival rate (MARK estimates) was $0.979 \pm 0.01$ during incubation and $0.878 \pm$ 0.04 during the nestling phase. The probability of survival during the entire nesting cycle was 0.206 .

Predation was the main cause of failure (55\% of the unsuccessful nests), followed by abandonment (30\%), infestation by Philornis (6\%), cattle trampling (6\%) and burning (3\%). We observed a Brazilian Green Racer Snake (Philodryas aestiva, Dipsadidae) preying two three-day-old nestlings. Predated nests were generally found in two forms: intact (most common pattern) or damaged (with holes, pulled apart or totally destroyed). The causes of nest desertion were not confirmed but were likely related to intense winds and rain that caused the females to leave the nests and eggs. Although we documented parasitism by Philornis seguyi in 27 nests, only three young died in two nests.

The most parsimonious models found include time-specific factors such as the linear time trend and, especially, nest age (Table I). Only the temporal variables were related to daily nest survival rate. DSR was independent of the five ecological variables measured and their $A I C$ values were higher than that of the null model when treated without the addition of the variable of nest age (Table I, second set). Only two of the candidate models received substantial support, with Akaike weights summing 0.48 (Table I). Although the model with only the nest age variable is better than the linear + nest age model, it is necessary to consider the penalty caused by the additional parameter of the latter, even though the better model has 1.78 $\mathrm{AIC}_{c}$ units less. The logistic regression equation for this best model was simply Logit $(\hat{S})=5.26$ - 0.18 (nest age). However, we found that DSR decreases over the reproductive season and that it decreases rapidly with the increasing age of the nests (Figure 1).

Daily nest survival values were negatively correlated with maximum daily temperature in the study area $(P=0.001)$, which gradually increases between November (monthly average $19.9 \pm 4.2^{\circ} \mathrm{C}$ ) and February (monthly average = $22.9 \pm 2.54^{\circ} \mathrm{C}$ ).

\section{DISCUSSION}

We found that nest age was the most relevant factor to survival in Sporophila hypoxantha nests, with DSR sharply falling over the nesting cycle (Figure 1a). In this species, the frequency of visits to the nest are considerably higher during the 
Table I. Model for DSR indicating (a) time trend and (b) the determinants of daily survival for nests of Tawnybellied Seedeaters Sporophila hypoxantha in southern Brazilian grasslands, over three breeding seasons (20072010). AIC represents Akaike's Information Criterion corrected for small sample sizes. We excluded models with performance worse than the null model. ${ }^{\mathrm{a}} \mathrm{AIC}_{\mathrm{c}}=114.33$. ${ }^{\mathrm{b}} \mathrm{AIC}_{\mathrm{c}}=107.81 . \Delta \mathrm{AIC}_{\mathrm{c}}=$ difference between $\mathrm{AIC}_{\mathrm{c}}$ of each model and the top model; $K=$ number of parameters; $w_{i}=$ Akaike weight; $T=$ linear time trend; $T T$ = quadratic time trend; (.) = null model. Notations follow Dinsmore et al. (2002).

\begin{tabular}{|c|c|c|c|c|}
\hline Model & $\Delta \mathrm{AIC}_{\mathrm{c}}$ & $w_{i}$ & $\mathbf{K}$ & Deviance \\
\hline \multicolumn{5}{|l|}{ (a) Time trend } \\
\hline $\mathrm{S}_{T}$ & $0.00^{\mathrm{a}}$ & 0.49 & 2 & 110.30 \\
\hline$S_{\pi}$ & 1.00 & 0.29 & 3 & 109.27 \\
\hline$S_{(.)}$ & 1.74 & 0.20 & 1 & 114.06 \\
\hline \multicolumn{5}{|l|}{ (b) Linear trend + covariates } \\
\hline $\mathrm{S}_{\text {age }}$ & $0.00^{\mathrm{b}}$ & 0.34 & 2 & 103.78 \\
\hline $\mathrm{S}_{T+\text { age }}$ & 1.78 & 0.14 & 3 & 103.53 \\
\hline $\mathrm{S}_{T+\text { age + study site }}$ & 2.19 & 0.11 & 4 & 101.90 \\
\hline $\mathrm{S}_{T+\text { age }+ \text { nest concealment }}$ & 3.51 & 0.05 & 4 & 103.22 \\
\hline $\mathrm{S}_{T+\text { age + nest height }}$ & 3.52 & 0.05 & 4 & 103.23 \\
\hline $\mathrm{S}_{T+\text { age + plant height }}$ & 3.75 & 0.05 & 4 & 103.46 \\
\hline$S_{T+\text { age + plant cover }}$ & 3.82 & 0.05 & 4 & 103.53 \\
\hline $\mathrm{S}_{T+\text { age }+ \text { year }}$ & 4.19 & 0.04 & 5 & 101.85 \\
\hline $\mathrm{S}_{T+\text { age }+ \text { study site }+ \text { nest concealment }}$ & 4.21 & 0.04 & 5 & 101.88 \\
\hline $\mathrm{S}_{T+\text { age }+ \text { year }+ \text { study site }}$ & 4.57 & 0.03 & 6 & 100.17 \\
\hline $\mathrm{S}_{T+\text { age }+ \text { plant species }}$ & 4.74 & 0.03 & 5 & 102.40 \\
\hline$S_{T+\text { age }+ \text { year }+ \text { study site }+ \text { nest concealment }}$ & 6.62 & 0.01 & 7 & 100.15 \\
\hline $\mathrm{S}_{T+\text { age }+ \text { year }+ \text { plant species }}$ & 7.99 & 0 & 7 & 101.52 \\
\hline $\mathrm{S}_{\text {global }}$ & 11.59 & 0 & 11 & 96.74 \\
\hline $\mathrm{S}_{T}$ & 19.27 & 0 & 2 & 123.05 \\
\hline $\mathrm{S}_{T+\text { study site }}$ & 19.87 & 0 & 3 & 121.62 \\
\hline$S_{(.)}$ & 20.70 & 0 & 1 & 126.50 \\
\hline
\end{tabular}

nestling feeding period than during incubation (4-9 visits hr $^{-1}$ and 2 visits hr $^{-1}$, respectively; Franz \& Fontana 2013). Furthermore, provisioning visits per hour increase as nestlings develop and males care for the young particularly when they are more developed, after they reach four to five days of age (Facchinetti et al. 2008, Franz \& Fontana 2013). Therefore, nest activities clearly increase along the nesting cycle, which could aid diurnal predators to find the nests. This pattern is in agreement with the amply debated and partially tested Skutch hypothesis (see Introduction). Various studies have shown this tendency. Recently, Di Giacomo et al. (2011) found this condition in Strange-tailed Tyrants (Alectrurus risora) in open savannas of the eastern Chaco, Argentina. Both Brawn et al. (2011) and Auer et al. (2007), which studied various 

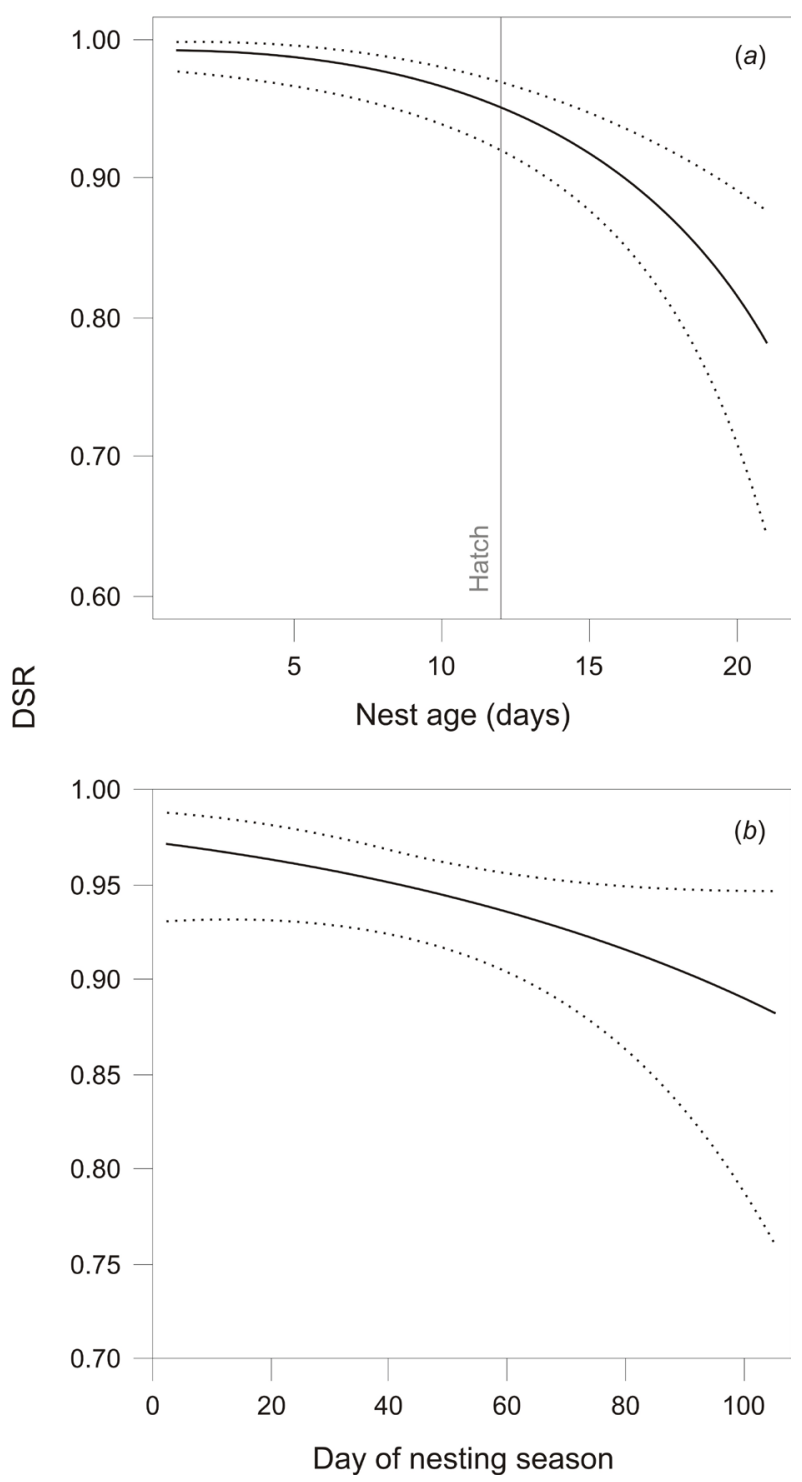

Figure 1. Estimated daily survival rates (DSR) of nests of the Tawny-bellied Seedeaters Sporophila hypoxanta during three breeding seasons (2007-2010), according to nest age (a; through the 21-days nesting cycle: 12 of incubation and 9 of nestling) and day of nesting season ( $b$; respecting a linear time trend), calculated with program MARK by means of candidate models that include each predictor variable. Dashed lines represent $95 \%$ confidence limits.

passerine species in Panama and Argentina, respectively, found lower rates of survival during the nestling period than during incubation for some of the studied representatives (but see Segura \& Reboreda 2012). França \& Marini
(2009), in the first study modeling survival of nests of Brazilian birds, reported the decrease in survival over the nesting cycle of Chapada Flycatchers (Suiriri islerorum). DSR in the Blackbellied Seedeater was also time dependent, but also was influenced by nest site characteristics (Rovedder 2011). Similarly, Lined and Doublecollared Seedeater nests have a higher probability of survival during the incubation period than during nestling rearing (Francisco 2006, Oliveira et al. 2010). Rosoni et al. (2019) found a similar pattern for the Rusty-collared Seedeater (Sporophila collaris) in grasslands of southern Brazil, with DSR decreasing with nest age. Although some studies support Skutch's theory (Martin et al. 2000b, Muchai \& Du Plessis 2005), others search for alternatives (Segura \& Reboreda 2012). Roper \& Goldstein (1997) argued against the theory based on an experiment in which they demonstrated that predation does not increase with increased nest activity and the principal predators are nocturnal and not visually oriented.

The Linear time trend model was the temporal model that best explained our data and indicated that the DSR decreases over the breeding season (Figure $1 \mathrm{~b}$ ). This pattern can be seen in many species. Grant et al. (2005) monitored the nests of two passerine species in North Dakota and found a better model for both species that considers only nest age (but with a cubic effect) and a second best model that also included a linear time trend. Sporophila melanogaster (Rovedder 2011), Stripe-tailed Yellow-finches (Sicalis citrina; Gressler 2007) and Alectrurus risora (Di Giacomo et al. 2011) also reflected this linear effect on DSR. Sporophila collaris also presented a linear time trend, but with DSR increasing over the breading season (Rosoni et al. 2019). In the present study, we exclude the ideas that this pattern is due to the occurrence of renesting 
because this rarely occurs with this species in the study area (Franz \& Fontana 2013) or a decrease in protective cover (Davis 2005), since the shrubs and surrounding vegetation do not change during the months of study. Alterations in the predator community (Grant et al. 2005) and food resource availability were not tested. As seen, temperature increases throughout the season and, consequently, so does intensity of nestling parasitism by subcutaneous Philornis larvae. This could potentially reduce the DSR as the end of the breeding season approaches (Skutch 1985, Grant et al. 2005).

We included in the experimental design the hypothesis that the daily survival rates of Tawnybellied Seedeater nests was not influenced by height above ground, support plant species and nest concealment which is possibly caused by low amount of variation in the measured values of these variables. Nests are higher than $25 \mathrm{~cm}$ and lower than $60 \mathrm{~cm}$ (Franz \& Fontana 2013), and perhaps this variation is not sufficient in providing an effect on the differential access capacity to nests by predators. The same theory could serve for the support plants, which are structurally similar (more than $80 \%$ of the nests were in the shrubs Vernonanthura chamaedrys e Symphyopappus compressus; Franz \& Fontana 2013), and thus vary little with respect to nest concealment.

The estimated reproductive success for Tawny-bellied Seedeaters in southern Brazil (40\% of apparent success and $20 \%$ of MARK survival) is similar to that found in other species of Sporophila seedeaters, although only a few studies are available. In the only study of reproductive success in the "capuchinos group" (a clade of small and colorful seedeaters composed by our study species and 11 others), Rovedder (2011) obtained an apparent reproductive success of $42 \%$ and a Mayfield success of $21 \%(n=64)$ for the Black-bellied
Seedeater (S. melanogaster), which is also found in Brazilian subtropical grasslands. Francisco (2006) found an apparent success of $36 \%(n=41)$ for the Double-collared Seedeater (S. caerulescens) in southeastern Brazil. In this same region, the apparent success of Lined Seedeaters (S. lineola) was higher $(56 \%, n=$ 41; Oliveira et al. 2010). Blue-black Grassquits (Volatinia jacarina), a closely related species that nests in open areas, had a lower success (24\%, $n=81$ ) in central Brazil (Aguilar et al. 2008). Skutch (1985) found a success of $54.5 \%$ $(n=44)$ in nests of the Variable Seedeater (S. ["aurita"] corvina), in Costa Rica. Chestnutthroated Seedeaters (S. telasco) had a success of 37\% $(n=190)$ in Equador (Marchant 1960). The $40 \%$ success found for $S$. hypoxantha (between $36 \%$ and $56 \%$ for Sporophila seedeaters studied up to today) can be considered median, within the normal range and close to the average for tropical birds.

As expected, predation was the principal cause of nest failure and affected 55\% of the unsuccessful nests (33\% of the total). The rate of predation is more closely related to the pattern found in birds of north-temperate zones (40-60\%, Martin 1993) than with the high predation pressure exerted on tropical zones (55-85\%; Stutchbury \& Morton 2001 but see Oniki 1979). This apparent reduced predation rate may be related to the efficient camouflage of the nests in general compared to syntopic species. In the same area, nests of other shrubnesting species such as the Bearded Tachuri (Polystictus pectoralis) that are more visible in the vegetation have higher rates of predation (Fontana et al. unpubl. data). Characteristics of the vegetation near nests influence the probability of predation (Martin \& Roper 1988, Martin 1993, Roper 2000, Fontaine et al. 2007). Additionally, behavioral adjustments due to the risk of predation (Fontaine \& Martin 2006) 
seem to be efficient and cause nesting activities to be more inconspicuous. Roper et al. (2010) state that individuals that are under lower than average predation risks may be favored in the selection that leads to lower predation rates.

All cases of nest desertion occurred during the incubation period $(n=7)$ or nest construction $(n=3)$, and this is the second most important cause of nest failure, affecting 30\% of unsuccessful nests. Desertion is likely related to the locally frequent rainstorms, but may also include lack of food resources (Ricklefs 1969), or parents' perceiving risk of predation (Berger-Tal et al. 2010, Zanette et al. 2011).

Parasitism by Philornis seguyi (Diptera) may importantly influence survival as it occurred in $61 \%$ of nests with Tawny-bellied Seedeaters nestlings. Philornis seguyi is known to have negative effects of infestations on chick survival and nestling growth of other birds (Rabuffetti \& Reboreda 2007, Segura \& Reboreda 2011). In Tawny-bellied Seedeaters, mortality occurred in only three nestlings (two of them had 24 and 26 larvae; Franz \& Fontana 2013) suggesting that infestations of more than 20 larvae per nestling may be lethal as we documented that nestlings with between five and 17 larvae fledged successfully. Philornis may also influence survival of other seedeater species such as $S$. americana, S. lineola, S. angolensis, S. nigricollis, S. angolensis, S. bouvreuil, S. intermedia and S. caerulescens (Gross 1952, Dodge \& Aitken 1968, Löwenberg-Neto 2008) for which other Philornis species have been reported.

Analyzing the nest survival of the Tawnybellied Seedeater in relation to temporal and environmental variables over three breeding seasons in Brazilian subtropical grasslands we show that best models include time-specific factors as nest age and time of breeding season, reflected by a gradual reduction in nest survival over the nesting cycle, accompanied by an increase in temperature, subcutaneous larvae infestation, and predation. This conclusion is important to plan on seasonally dependent conservation and management measures in a region facing harmful land-use and climate changing. We consider the study areas to be of utmost importance in the conservation of this species and others that reproduce in or utilize the region as a stopover during migration. Finally, we suggest more studies with grasslanddependent South American birds, especially those endangered species with medium-low breeding success and productivity, in order to identify their ecological and biological requirements.

\section{Acknowledgments}

We thank Jay J. Rotella (Montana State University) for help with processing the data and interpreting the results in program MARK and R code. Reviews by James J. Roper, Jeferson Vizentin-Bugoni, Juan C. Reboreda, Leonardo F. França and two anonymous reviewers consistently improved an earlier version of the manuscript. Cristiano E. Rovedder, Márcio Repenning and Mariana L. Gonçalves for their assistance with fieldwork. Márcio Borges-Martins (Universidade Federal do Rio Grande do Sul) for snake identification. Márcia Souto Couri (Universidade Federal do Rio de Janeiro) for Philornis identification. Joaquim and Nair, Antônio and Ivonete for logistic support and permission to work in their properties. Conselho Nacional de Desenvolvimento Científico e Tecnológico (CNPq) and Coordenação de Aperfeiçoamento de Pessoal de Nivel Superior (CAPES) for the scholarship for IF. Funding was provided by Fundação Grupo Boticário de Proteção à Natureza (project no. 0795-20082) and Neotropical Grassland Conservancy.

\section{REFERENCES}

AGUILAR TM, DIAS RI, OLIVEIRA AC \& MACEDO RH. 2008. Nestsite selection by Blue-black Grassquits in a Neotropical savanna: do choices influence nest success? J Field Ornithol 79: 24-31.

AINLEY DG \& SCHLATTER RP. 1972. Chick raising ability in Adelie Penguins. The Auk 89: 559-566. 
AUER SK, BASSAR RD, FONTAINE JJ \& MARTIN TE. 2007. Breeding biology of passerines in a subtropical montane forest in northwestern Argentina. The Condor 109: 321-333.

AYRES M, AYRES JR. M, AYRES DL \& SANTOS AA. 2007. BioEstat. Version 5.0. USP, São Paulo, Brazil.

BEIER C, REPENNING M, PEREIRA MS, PEREIRA A \& FONTANA CS. 2017. Cooperative breeding and demography of Yellow Cardinal Gubernatrix cristata in Brazil. Rev Bras Ornitol 25(1): 12-19.

BERGER-TAL R, BERGER-TAL O \& MUNRO K. 2010. Nest desertion by Grey Fantails during nest building in response to perceived predation risk. J Field Ornithol 81: 151-154.

BOLKER BM. 2011. Ecological models and data in R. Princeton New Jersey: University Press.

BRAWN JD, ANGEHR G, DAVROS N, ROBINSON WD, STYRSKY JN \& TARWATER CE. 2011. Sources of variation in the nesting success of understory tropical birds. J Avian Biol 42: 61-68.

BURNHAM KP \& ANDERSON DR. 2002. Model selection and multimodel inference: a practical information-theoretic approach, $2^{\text {nd }}$ ed., New York: Springer-Verlag.

DAVIS SK. 2005. Nest-site selection patterns and the influence of vegetation on nest survival of mixed-grass prairie passerines. The Condor 107: 605-616.

DI GIACOMO AG. 2005. Aves de la Reserva El Bagual. In: Di Giacomo AG \& Krapovickas SF (Eds), Historia natural y paisage de la Reserva El Bagual. Temas de Naturaleza y Conservación 4, p. 201-465.

DI GIACOMO AS, DI GIACOMO AG \& REBOREDA JC. 2011. Male and female reproductive success in a threatened polygynous species: the Strange-tailed Tyrant, Alectrurus risora. The condor 113: 619-628.

DINSMORE SJ, WHITE GC, \& KNOPF FL. 2002. Advanced techniques for modeling avian nest survival. Ecology 83 : 3476-3488.

DODGE HR \& AITKEN THG. 1968. Philornis flies from Trinidad (Diptera: Muscidae). J Kansas Entomol Soc 41: 134-154.

DOHERTY PF, WHITE GC \& BURNHAM KP. 2012. Comparison of model building and selection strategies. J Ornithol 151(Suppl. 2): S317-S323.

FACCHINETTI C, DI GIACOMO AG \& REBOREDA JC. 2008. Parental care in Tawny-bellied (Sporophila hypoxantha) and Rusty-collared (S. collaris) Seedeaters. Wilson J Ornithol 120: 879-883.
FONTAINE JJ \& MARTIN TE. 2006. Parent birds assess nest predation risk and adjust their reproductive strategies. Ecol Lett 9: 428-434.

FONTAINE JJ, MARTEL M, MARKLAND HM, NIKLISON AM, DECKER KL \& MARTIN TE. 2007. Testing ecological and behavioral correlates of nest predation. Oikos 116: 1887-1894.

FRANÇA LF \& MARINI MA. 2009. Low and variable reproductive success of a neotropical tyrant-flycatcher, Chapada Flycatcher (Suiriri islerorum). Emu 109: 265-269.

FRANCISCO MR. 2006. Breeding biology of the Doublecollared Seedeater (Sporophila caerulescens). Wilson J Ornithol 118: 85-90.

FRANZ I \& FONTANA CS. 2013. Breeding biology of the Tawny-bellied Seedeater (Sporophila hypoxantha) in southern Brazilian upland grasslands. Wilson J Ornithol 125(2): 280-292.

GRANT TA, SHAFFER TL, MADDEN EM \& PIETZ PJ. 2005. Timespecific variation in passerine nest survival: new insights into old questions. The Auk 122: 661-672.

GRESSLER DT. 2007. Biologia e sucesso reprodutivo de Sicalis citrina Pelzeln, 1870 (Aves: Emberizidae) no Distrito Federal. MSc. dissertation, Universidade de Brasília, Brasília, DF, Brazil. (Unpublished).

GROSS AO. 1952. Nesting of Hick's Seedeater at Barro Colorado island, Canal Zone. The Auk 69: 433-446.

ICMBIO. 2018. Livro Vermelho da fauna brasileira ameaçada de extinção. Volume III - Aves. Brasília: ICMBio/MMA.

IGANCI JRV, HEIDEN G, MIOTTO STS \& PENNINGTON RT. 2011. Campos de Cima da Serra: the Brazilian Subtropical Highland Grasslands show an unexpected level of plant endemism. Bot J Linn Soc 167: 378-393.

LACK D. 1947. The significance of clutch size. Parts I and II. Ibis 89: 302-352.

LÖWENBERG-NETO P. 2008. The structure of the parasitehost interactions between Philornis (Diptera: Muscidae) and neotropical birds. J Tropi Ecol 24: 575-580.

MARCHANT S. 1960. The breeding of some S.W. Ecuadorian birds. Ibis 102: 584-599.

MARTIN TE. 1993. Nest predation among vegetation layers and habitat types: revising the dogmas. Amer Natural 141: 897-913.

MARTIN TE. 1995. Avian life history evolution in relation to nest sites, nest predation and food. Ecol Monogr 65: $101-127$ 
MARTIN TE. 1996. Life history evolution in tropical and south temperate birds: what do we really know? J Avian Biol 27: 263-272.

MARTIN TE. 2004. Avian life-history evolution has an eminent past: dos it have a bright future? The Auk 121: 289-301.

MARTIN TE. 2011. The cost of fear. Science 334: 1353-1354.

MARTIN TE \& GEUPEL GR. 1993. Nest-monitoring plots: methods for locating nests and monitoring success. J Field Ornithol 64: 507-519.

MARTIN TE \& ROPER JJ. 1988. Nest predation and nest-site selection of a western population of the Hermit Thrush. The Condor 90: 51-57.

MARTIN TE, MARTIN PR, OLSON CR, HEIDINGER BJ \& FONTAINE JJ. 2000a. Parental care and clutch sizes in North and South American birds. Science 287: 1482-1485

MARTIN TE, SCOTT J \& MENGE C. 2000b. Nest predation increases with parental activity: separating nest site and parental activity effects. Proc Royal Soc B (Biol Sci). 267: 2287-2293.

MOREAU R. 1944. Clutch size: a comparative study, with reference to African birds. Ibis 86: 286-347.

MUCHAI M \& DU PLESSIS MA. 2005. Nest predation of grassland bird species increases with parental activity at the nest. J Avian Biol 36: 110-116.

OLIVEIRA LS, SOUSA LMS, DAVANÇO PV \& FRANCISCO MR. 2010. Breeding behavior of the Lined Seedeater (Sporophila lineola) in southeastern Brazil. Ornitol Neotrop 21: 251-261.

ONIKI Y. 1979. Is nesting success of birds low in the Tropics? Biotropica 11: 60-69.

R DEVELOPMENT CORE TEAM. 2011. R: A language and environment for statistical computing. R Foundation for Statistical Computing, Vienna, Austria. http://www.Rproject.org/.

RABUFFETTI FL \& REBOREDA JC. 2007. Early infestation by bot flies (Philornis seguyi) decreases chick survival and nesting success in chalk-browed mockingbirds (Mimus saturninus). The Auk: 898-906.

REPENNING M \& FONTANA CS. 2016. Breeding biology of the Tropeiro Seedeater (Sporophila beltoni). The Auk: Ornithol Adv 133: 484-496.

RICKLEFS RE. 1969. An analysis of nesting mortality in birds. Smithsonian Contrib Zool 9: 1-47.

ROBINSON WD, HAU M, KLASING KC, WIKELSKI M, BRAWN JD, AUSTIN SH, TARWATER CE \& RICKLEFS RE. 2010. Diversification of life histories in New World birds. The Auk 127: 253-262.
ROPER JJ. 1992. Nest predation experiments with quail eggs: too much to swallow? Oikos 65: 528-530.

ROPER JJ. 2000. Experimental analysis of nest-sites and nest predation for a neotropical bird: stuck between a rock and a hard place. Ararajuba 8: 85-91.

ROPER JJ \& GOLDSTEIN RR. 1997. A test of the Skutch Hypothesis: does activity at nests increase predation risk? J Avian Biol 28: 111-116.

ROPER JJ, SULLIVAN KA \& RICKLEFS RE. 2010. Avoid nest predation when predation rates are low, and other lessons: testing the tropical-temperate nest predation paradigm. Oikos 119: 719-729.

ROSONI JRR, KRÜGEL MM, FONTANA CS \& BEHR ER. 2019. Breeding biology of Rusty-collared Seedeater (Sporophila collaris) in the grasslands in southern Brazil. Wilson J Ornithol131: 296-309.

ROTELLA J. 2011. Nest survival models (Chapter 17), p. 17/2-17/21. In: Cooch E \& White G (Eds), Program MARK: a gentle introduction, 11 ed. <http://www.phidot.org/ software/mark/index.html>

ROVEDDER CE. 2011. História natural de Sporophila melanogaster (Pelzeln 1870) (Aves: Emberizidae) com ênfase em sua biologia reprodutiva. MSc. dissertation, Pontifícia Universidade Católica do Rio Grande do Sul, Porto Alegre, RS, Brazil. (Unpublished).

SEBER GAF. 1982. The estimation of animal abundance and related parameters. 2 ed., New York: Chapman, London and Macmillan.

SEGURA LN \& REBOREDA JC. 2011. Botfly parasitism effects on nestling growth and mortality of Red-crested Cardinals. Wilson J Ornithol 123: 107-115.

SEGURA LN \& REBOREDA JC. 2012. Nest survival rates of Red-crested Cardinals increase with nest age in southtemperate forests of Argentina. J Field Ornithol 83: 343-350.

SILVA JMC. 1999. Seasonal movements and conservation of seedeaters of the genus Sporophila in South America. Studies in Avian Biology 19.

SKUTCH AF. 1949. Do tropical birds rear as many young as they can nourish? Ibis 91: 430-455.

SKUTCH AF. 1985. Clutch size, nesting success, and predation on nests of neotropical birds, reviewed. Ornithol Monogr 36: 575-594.

SLAGSVOLD T. 1982. Clutch size variation in passerine birds: the nest predation hypothesis. Oecologia 54: 159-169.

STUTCHBURY BJM \& MORTON ES. 2001. Behavioral ecology of tropical birds. San Diego: Academic Press. 
STUTCHBURY BJM \& MORTON ES. 2008. Recent advances in the behavioral ecology of tropical birds. Wilson J Ornithol 120: 26-37.

WHITE GC \& BURNHAM KP. 1999. Program MARK: survival estimation from populations of marked animals. Bird Study 46: 120-139.

WILLIS EO. 1974. Populations and local extinctions of birds on Barro Colorado Island, Panamá. Ecol Monogr 44: 153-169.

ZANETTE LY, WHITE AF, ALLEN MC \& CLINCHY M. 2011. Perceived predation risk reduces the number of offspring songbirds produce per year. Science 334: 1398-1401.

\section{How to cite}

FRANZ I \& FONTANA CS. 2021. Drivers of nest survival in the Tawnybellied Seedeater Sporophila hypoxantha (Aves: Thraupidae): timespecific factors are more related to success than ecological variables. An Acad Bras Cienc 93: e20191458. DOI 10.1590/0001-3765202120191458.

Manuscript received on November 29, 2019;

accepted for publication on December 16, 2020

\section{ISMAEL FRANZ ${ }^{1,2}$}

https://orcid.org/0000-0003-3382-0403

\section{CARLA S. FONTANA}

https://orcid.org/0000-0001-9423-0752

'Universidade Federal do Rio Grande do Sul, Departamento de Zoologia, Av. Bento Gonçalves, 9500, 91501-970 Porto Alegre, RS, Brazil

${ }^{2}$ Pontifícia Universidade Católica do Rio Grande do Sul, Programa de Pós-Graduação em Ecologia e Evolução da Biodiversidade, Escola de Ciências, Av. Ipiranga, 6681, 90619-900 Porto Alegre, RS, Brazil

\section{Correspondence to: Ismael Franz}

E-mail:franz@ufrgs.br

\section{Author contributions}

Ismael Franz was responsible for the funding acquisition, project conceptualization, field data collection, analysis, figure production, writing and review. Carla S. Fontana was responsible for the funding acquisition, project conceptualization, writing and review.

\section{(c) BY}

